\title{
UTERINE ANGIOLEIOMYOMAS: A REPORT OF 2 CASES
}

Manimekhala. P, Sumanth Kumar. D, Ramani. M, Krishna Reddy.C. H, Ratna Kumari.V
1. Associate Professor. Department of Pathology, Niloufer Hospital for Woman and Children.
2. Post Graduate. Department of Pathology, Niloufer Hospital for Woman and Children.
3. Professor. Department of Pathology, Niloufer Hospital for Woman and Children.
4. Post Graduate. Department of Pathology, Niloufer Hospital for Woman and Children.
5. Professor, Department of Obstetrics \& Gynaecology, Niloufer Hospital for Woman and Children.

\section{CORRESPONDING AUTHOR:}

Dr. Manimekhala.P,

Associate Professor,

Department of Pathology,

Osmania general hospital, Hyderabad.

E-mail: manimekhalarao@gmail.com

Angioleiomyomas are relatively common neoplasms in skin and superficial planes of extremities (89\%), head (48\%) and trunk (14\%). These tumours are extremely rare in uterus with very few cases described in the literature. These cases have been described with varied names like angiomyoma, angioleiomyoma, or vascular leiomyoma. There is no description of angioleiomyoma as an entity or as a variant of leiomyoma in the latest WHO classification of uterine tumours. There is a mention of vascular leiomyoma as a differential diagnosis of hemangioma under rare mesenchymal tumors but no description provided. A proposal has been made by Glenn Mc Cluggage et.al that angioleiomyoma should be included among the benign leiomyoma variants in the next WHO classification.

KEY WORDS: Angioleiomyoma, Leiomyoma, Uterine.

CASE REPORTS: Angioleiomyomas are relatively common neoplasms in skin and superficial planes of extremities (89\%), head (48\%) and trunk (14\%)(1). We report 2 cases of angioleiomyomas in our institute. Hysterectomy was done in both these cases Hematoxylin and Eosin stained slides were examined. Immunohistochemistry was performed with the smoothmuscle markers $\alpha$ Smooth Muscle Actin $(\alpha S M A)$, Desmin, proliferation marker Ki-67 and melanoma associated marker HMB45.

CLINICAL FEATURES: CASE 1: Twenty eight year old Indian women who had history of two previous lower segment caesarean section presented to the gynaecology outpatient department with the complaints of secondary amenorrhea since 1 year. Amenorrhea was preceded by oligomenorrhoea. Ultrasonography showed a large solid degenerating mass in the fundus of uterus. Pap smear was normal. Total abdominal hysterectomy was done and the ovaries were retained. The uterus was 18 weeks size intraoperative. Both tubes and ovary appeared normal. Uterus was submitted for histopathology examination in $10 \%$ formalin.

GROSS FINDINGS: Uterus was bulky and uterine cavity was obliterated by multiple fibroids. The unaffected myometrium measured $2 \mathrm{~cm}$ in thickness and endometrium was not discernable grossly. There was a submucous fibroid from the posterior uterine wall measuring $15 \mathrm{~cm} \times 20$ $\mathrm{cm}$. Cut section from this fibroid showed degeneration and the tissue was friable. There was another fibroid which was intramural measuring $9 \mathrm{~cm} \times 5 \mathrm{~cm} \times 4 \mathrm{~cm}$ in dimensions. Cut section of 
this fibroid was fleshy and variegated with grey white to gray tan areas. Cervix showed nabothian cyst.

CASE 2: Forty five year old Indian women with history of six normal deliveries and an abortion presented to gynaecology outpatient department with excessive uterine bleeding, about 5 pads per day and leucorrhoea. She was pale on general examination and had a history of one unit blood transfusion. Ultrasonography was done which showed a small calcified sub serous fibroid with cystic degeneration in uterus and free fluid in abdomen. Laparoscopy assisted vaginal hysterectomy was performed and uterus specimen sent for histopathological examination in $10 \%$ formalin.

GROSS FINDINGS: Uterus showed a fundal sub serous fibroid measuring $2 \mathrm{~cm} \mathrm{x} 1 \mathrm{~cm}$. Cut section of the fibroid showed cystic degeneration and solid areas showed white whorled appearance. Cervix showed a nabothian cyst. Endometrium measured $0.2 \mathrm{~cm}$ and myometrium $2.5 \mathrm{~cm}$ in thickness.

MICROSCOPIC EXAMINATION: Histological sections of the tumors, stained by haematoxylin and eosin of both the patients, who had varied clinical presentation showed similar picture. Tumour tissue was well circumscribed, moderately cellular with well demarcated nodules of whorled and interlacing fascicles of uniform fusiform spindle cells intermingling with thickened blood vessels. The outer smooth muscle cells of the blood vessels swirled away from the vessel wall and merged with and were indistinguishable from the tumour cells. Few vessels showed fibrin deposition within the walls. Individual tumour cells appeared bland with blunt ended cigar shaped nucleus and eosinophilic cytoplasm. There were focal areas of mild cellular atypia and slight increase in the mitotic activity about 3-4 per 10 high power fields in the first case. Both showed areas of myxoid and hyaline degeneration.

There was no significant pathologic abnormality in the remainder of uterus and cervix in both the cases.

IMMUNO-HISTOCHEMISTRY: Tumour cells in both cases were strongly positive for $\alpha$ SMA (Smooth Muscle Actin) and Desmin and negative for melanocyte related marker HMB 45 (Human Melanocyte Black).

DISCUSSION: Angioleiomyomas though relatively common elsewhere, very few cases have been described in uterus $(2,3,4,5,6,7,8)$. Here we present two cases of angioleiomyoma which occurred with different clinical presentations but both showing similar histopathological and immunohistochemical features. The histopathological features were similar to the skin tumours bearing the name. Usual leiomyomas can have blood vessels but our cases had unusually many blood vessels which were evenly distributed and had thickened wall. A distinct karyotypic alteration was reported in angioleiomyoma which was never reported before in usual leiomyomas ${ }^{9}$. We agree with Glenn Mc Cluggage et.al that these cases may have been under reported due to sheer benignity of the tumour and support the opinion of including angioleiomyomas as a distinct variant in the WHO classification². 


\section{REFERENCES:}

1. Hachisuga T, Hashimoto H, Enjoji M.Angioleiomyoma. A clinicopathologic reappraisal of 562 cases. Cancer 1984 Jul 1; 54(1):126-30.

2. McCluggage WG, Boyde A. Uterine angioleiomyomas: a report of 3 cases of a distinctive benign leiomyoma variant. Int J Surg Pathol. 2007 Jul; 15(3):262-5.

3. Culhaci N, Ozkara E, Yuksel H, Ozsunar Y, Unal E. Spontaneously ruptured uterine angioleiomyoma. Pathol Oncol Res. 2006; 12:50-1.

4. Hsieh CH, Lui CC, Huang SC, et al. Multiple uterine angioleiomyomas in a woman presenting with severe menorrhagia. Gynecol Oncol. 2003; 90:348-2.

5. Jameson CF. Angiomyoma of the uterus in a patient with tuberous sclerosis. Histopathology. 1990; 16:202-3.

6. Konichezky M, Reif R, Bukovsky I. Benign angiomyoma of the uterus with usual macroscopic appearance. Int J Gynecol Obstet. 1980; 18:4-6.

7. Sakai Y. Epithelioid vascular leiomyoma of the uterus mimicking glomangioma. Arch Gynecol Obstet. 2006; 275:59-6.

8. Sunitha Thomas, Laxmi Radhakrishnan, Latha Abraham, and Anna Mattha. Case Case ReportUterine Angioleiomyoma with Atypia, Raised CA-125 Levels, and Pseudo-Meigs Syndrome: An Alarming Presentation. Reports in Pathology Volume 2012 (2012), Article ID 519473, 4 pages doi:10.1155/2012/519473.

9. Hennig Y, Caselitz J, Stern C, Bartnitzke S, Bullerdiek J. Karyotype evolution in a case of uterine angioleiomyoma. Cancer Genet Cytogenet. 1999 Jan 1; 108(1):79-80.

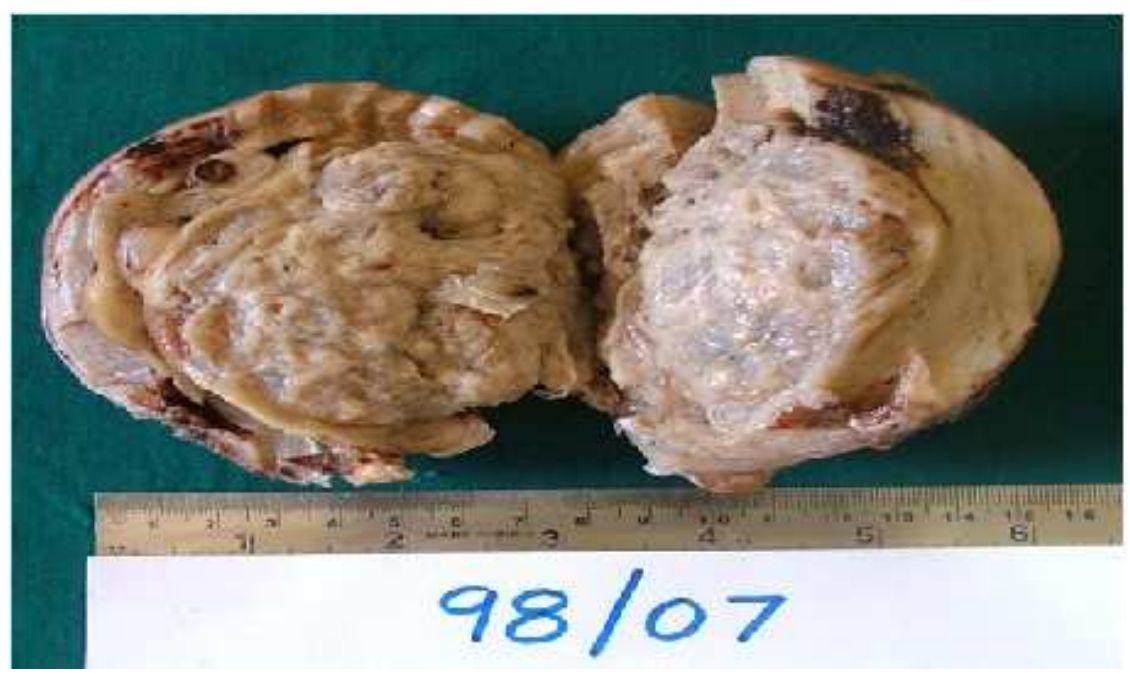

Figure 1: Gross picture of intramural fibroid in case 1 showing fleshy variegated appearance with grey white and grey tan areas. 


\section{CASE REPORT}

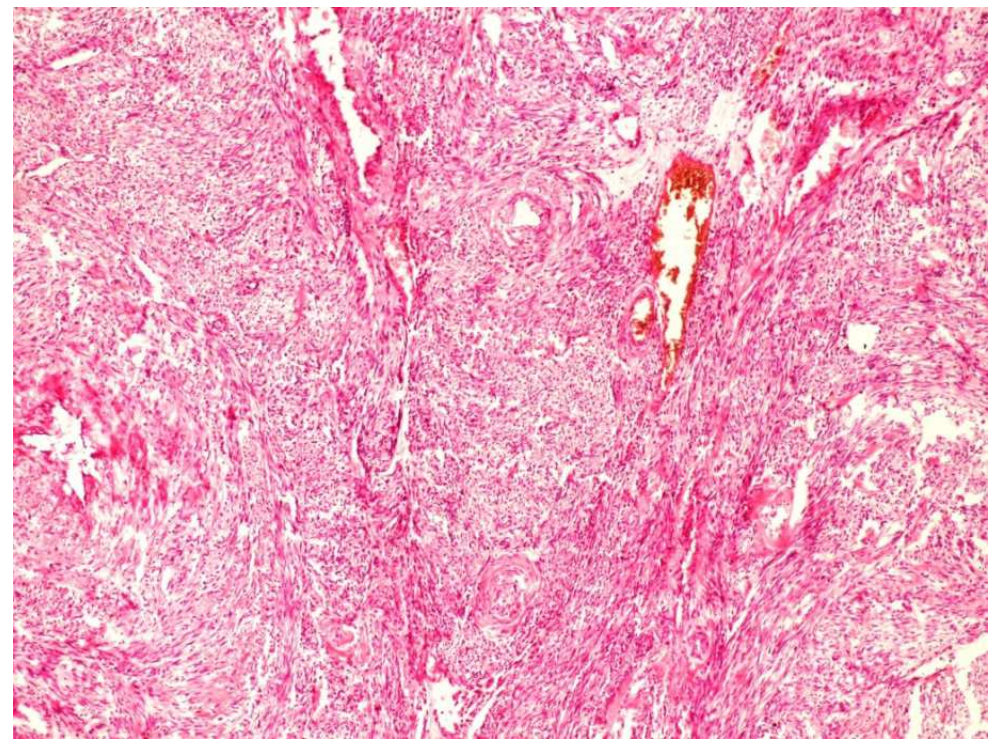

Fig-2 Low Power View: Small vascular channels with thick and muscular walls surrounded by mature smooth muscle.

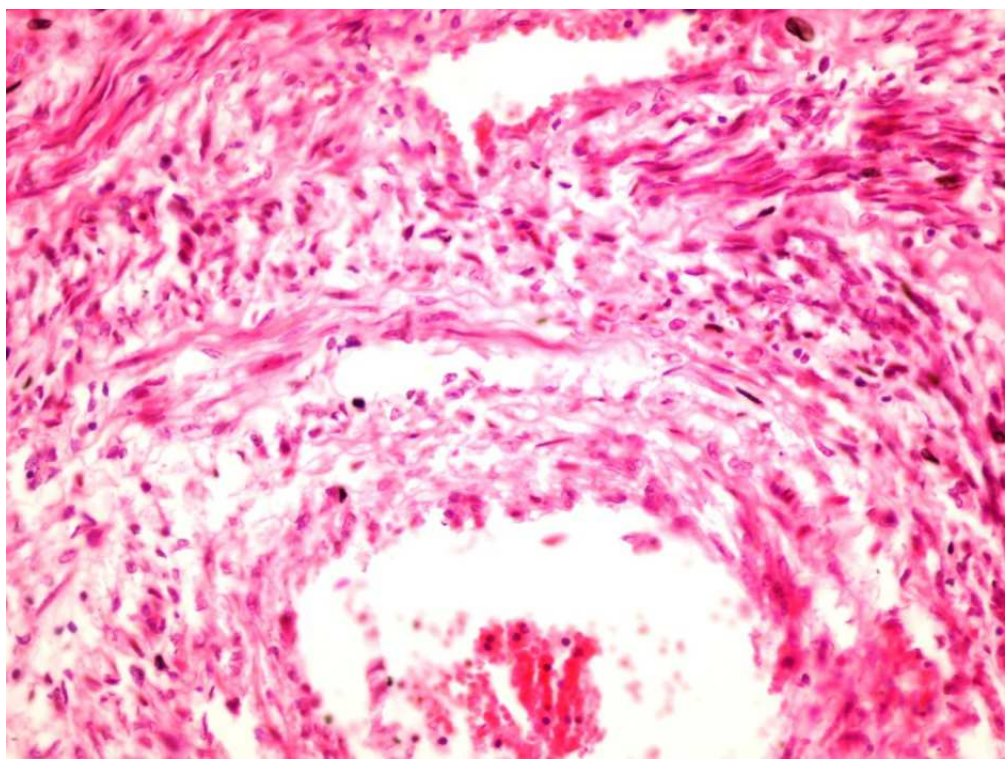

Fig-3 High Power View: Swirling of spindle cells around the blood vessels. 